\title{
Documentation and analysis of traumatic injuries in clinical forensic medicine involving structured light three-dimensional surface scanning versus photography
}

\begin{abstract}
Non-contact three-dimensional (3D) surface scanning has been applied in forensic medicine and has been shown to mitigate shortcoming of traditional documentation methods. The aim of this paper is to assess the efficiency of structured light 3D surface scanning in recording traumatic injuries of live cases in clinical forensic medicine. The work was conducted in Medico-Legal Centre in Benghazi, Libya. A structured light 3D surface scanner and ordinary digital camera with close-up lens were used to record the injuries and to have $3 \mathrm{D}$ and twodimensional (2D) documents of the same traumas. Two different types of comparison were performed. Firstly, the 3D wound documents were compared to 2D documents based on subjective visual assessment. Additionally, 3D wound measurements were compared to conventional measurements and this was done to determine whether there was a statistical significant difference between them. For this, Friedman test was used. The study established that the 3D wound documents had extra features over the 2D documents. Moreover; the 3D scanning method was able to overcome the main deficiencies of the digital photography. No statistically significant difference was found between the 3D and conventional wound measurements. The Spearman's correlation established strong, positive correlation between the 3D and conventional measurement methods. Although, the 3D surface scanning of the injuries of the live subjects faced some difficulties, the 3D results were appreciated, the validity of 3D measurements based on the structured light 3D scanning was established. Further work will be achieved in forensic pathology to scan open injuries with depth information.
\end{abstract}

\section{Keywords}

Structured light 3D surface scanner; photography; wound documentation; clinical forensic medicine.

\section{Introduction}

Forensic wound documentation is an important task in clinical forensic setting, such recordings serve many functions including sources of interpretation by examiners, evidences for written medico-legal reports, sources of measurements (wound dimensions or wound area). They are also used to match patterned injuries to suspected causative instruments. Ultimately 
such recordings may be used to represent the injuries (which may have since healed) in court. All these roles assist the examiners and support prosecution and the court in its decisionmaking.

Although the digital photography is a common method for wound documentation, it can be easily affected by certain factors, such as distance and lighting condition. Very close-up distance causes $3 \mathrm{D}$ objects to appear out of focus, proximity effect. ${ }^{1}$ The lighting condition is also a serious factor, not easy to control during the photography. ${ }^{2-7}$ Digital photos can also be featured distortions, noise and technical errors. Such distortions have been categorized by Evans et al. ${ }^{8}$ into four types: angular distortion and other three types of scale distortions. Noise is a random signal, destroys some parts of image information. Many different types of the noise can occur during the imaging steps, and they are very difficult to remove. The noise originates from different sources, such as Charge Coupled Devices (CCD), inaccurate cameras and misaligned lenses. ${ }^{9}$ Examples include, photon noise, electronic noise, impulse noise, periodic noise, quantization noise and coloured noise. ${ }^{9,10}$ The technical errors may result from improper camera adjustment of the aperture, shutter speed and white balance which can cause wrong exposure or distorted colour. ${ }^{2}$

Forensic wound measurements are important descriptions in the medico-legal reports particularly for injured live victims. They are a record of wound severity and the degree of the force used. In addition, the overlay matching depends on the accurate measurements. ${ }^{11}$ In clinical forensic medicine, a ruler and measurement method that relies on digital photographs are commonly used methods.

Although the ruler method is a simple and widely used, it has serious disadvantages summarized in following points:

-It is a subjective method, limited by inter-observer variability. ${ }^{12-15}$ Determining the greatest wound diemensions can be varible from one examiner to another, ${ }^{5}$ especially if the wound is irregular. ${ }^{16,17}$

-It is clearly affected by movements and change in the subject position. ${ }^{18}$

-It overestimates the wound area. Measurement of the wound area by multiplying two dimensions (the longest length $\mathrm{x}$ the widest width) assumes that the wound shape is rectangular or square ${ }^{3,7,14,15,17}$ and overestimates the actual area of the wound by $10 \%-44 \%$. $^{3,4,7}$ Thus, an ellipse formula (length $\mathrm{x}$ width $\mathrm{x}$ 0.785) is suggested to measure the area ${ }^{3,4,19}$; however, using this formula assumes that the wound's shape is ellipse. ${ }^{20}$

-It has an uncertain accuracy, ${ }^{12,13,21,22}$ especially with larger size and irregular shape wound. ${ }^{3,13}$ -It is a contact method, has risk of infection. 
-It has no permanent records. If the wound is healed, the measurements cannot be re-assessed for the second opinion.

Measurement method that relies on the digital photographs are accurate ${ }^{3,4,14}$ and reliable ${ }^{3,14}$; however, the method has some significant shortages which can limit its accuracy, ${ }^{23}$ these shortages include:

-Identification of wound border to calculate the area is subjective having a human contribution. ${ }^{3,5,18}$

-The wound border can be obscured ${ }^{3}$ by a scale, blood stain or an associated injury.

- It can under or overestimate the wound area. The image should be captured while the optical axis of the lens is perpendicular to the wound plane to obtain the actual site, size and shape of the wound. 2,3,24,25 Improper angle can have an influence on the wound view causing underestimation of the wound area by up to $10 \%-34.8 \%{ }^{3,25}$ The more change of the angle, the larger measurement error. ${ }^{25}$ Improper angle can also have an effect on the scale. The scale can appear larger or smaller according to its position at the photo (below or above the wound). If the scale appears smaller, the area is possibly overestimated. In the reality, acquiring the image in the exact recommended angle is unlikely to achieve as the camera is handheld to access the injuries that can be anywhere on the body. ${ }^{25}$

-Wounds on curved area can cause measurement errors. ${ }^{3,5,18,22,23}$ Even if the wound is fully recorded, the measurements will not be accurate as the optical methods ignore the normal surface curvature. ${ }^{18}$

- Researchers consider that the digital measurement method is contact less, has no risk of infection. ${ }^{3,7}$ However, it has an element of direct contact by placing the scale around the injury. -Preserving 3D injuries in the 2D photos reduces the 3D injuries into $2 \mathrm{D}$ level. ${ }^{3,26}$

Therefore, the conventional methods of the wound documentation and measurements are not satisfied for that reason there are recommendations to record the forensic injuries by noncontact 3D surface scanning methods. ${ }^{26-29}$ These methods scan the surface of the injuries and generate 3D models instead of the 2D images. They compute 3D coordinates $(x, y, z)$ of surface points $^{30}$ and create model with 3D surface geometry. There are passive and active 3D surface scanning. The passive scanning relies on taking series of photographs ${ }^{31}$ while the active scanning is based on projection of a laser beam or structured light patterns. ${ }^{32}$ These methods have been applied in many applications. In medicine, they have been used, for example, to record chronic wounds and take wound measurements. ${ }^{7,18,33,34}$ In forensic medicine, the active and passive 3D surface scanning have been applied for different aims, such as scanning of the injuries or external full-body. ${ }^{26,29,35-38}$ 
The structured light 3D surface scanning technique is relied on projection of highly designed light patterns with coding strategy that allows accurate correspondence between the projected image and the captured image. ${ }^{30,31,39-42}$ The structured light 3D surface scanning is based mainly on analysis of the distortion of the light patterns by the shape of the scanned object. $30,31,36,37,40,42,43$ While the passive 3D technology such as photogrammetry cannot obtain the same level of the technical accuracy of the active 3D surfaces scanners. ${ }^{5,27,44}$ It does not project coded light patterns; thus, finding correspondence between photos is more difficult. ${ }^{45}$ Also, the lighting condition may have an impact on photos matching. ${ }^{5,45} \mathrm{With}$ regard of the human body surface scanning, hairy and wet areas are difficult to record by the photogrammetry. ${ }^{37,38,45}$ While the structured light 3D surface scanning, the Pico Scan 3D scanner, is able to reconstruct hairy, wet areas and dark coloured (black) skin. ${ }^{46}$ Despite of corrections and recent advances of the passive 3D surface scanning method, their limitations may cause less accurate 3D results. ${ }^{5}$ The laser 3D surface scanning is not convenient to scan the live subjects due to the safety issue, ${ }^{46}$ slow speed 3D measurement ${ }^{37}$ and failure to digitise dark coloured surfaces. ${ }^{47}$

Therefore, the aim of this paper is to assess the effectiveness of the structured light 3D surface scanning in recording the injuries of live cases in clinical forensic medicine. A range of traumatic injuries were scanned and photographed. Two different types of comparison were performed; 1) comparison between the $3 \mathrm{D}$ results (3D models) and $2 \mathrm{D}$ results (2D photos) based on the subjective visual assessment, and 2) comparison between 3D wound measurements and conventional measurements to determine whether there was a statistical significant difference between them.

\section{Materials and methods}

\subsection{Setting of the study, participants and injuries}

The work was conducted in the Centre of Clinical Forensic Medicine in Benghazi city, Libya during April and May 2017. Injured live forensic cases were involved. Selection of participants was based on a defined set of criteria such as ages ( $\geq 18$ years). The subjects read a participant information sheet and signed an informed consent form. The work was conducted during the medico-legal examination in a private room. The different types of mild to moderate traumatic forensic injuries were recorded (blunt and sharp force injuries, and firearm injuries). The injuries of upper limb, lower limb and torso were included. A digital camera and structured light 3D surface scanner were used to record the same injuries in the same position. All recorded data were not identified.

\subsection{Documentation methods}


The structured light 3D surface scanner, the Pico Scan 3D scanner, was used to scan the injuries and obtain the 3D wound documents and the professional digital camera of Nikon D70 with close-up lens was used to have the $2 \mathrm{D}$ wound documents of the same injuries. The Pico Scan 3D scanner has been used in some forensic works and shown to be effective in scanning some materials of forensic interest, such as footwear impression, human skeleton remains as well as bare different areas of the human body of live subjects. ${ }^{46-49}$ It has also been used in non-Forensic work. ${ }^{50}$

\subsubsection{The Pico Scan 3D scanner}

It consists of a Pico LCD projector and a canon EOS 1100D camera. The projector has 800 x 600 pixels and the camera has 968 x 644 8bits. In each scan the projector emitted coded structured light patterns toward a wounded surface where the camera captured 14 images of the illuminated surface plus one-color textured mapping image (Fig.1), the acquisition speed was around 20s for each scan. The PicoScan3 software processed the acquired information and reconstructed a raw 3D data (point cloud) by using a phase measuring profilometry (PMP). The scale was not required to place around the wounded area during the acquisition time.



Fig. 1. Some captured images by the Pico Scan 3D scanner. The wounded area illuminated with structured light patterns, pulse a color textured image. 
The scanning was preceded by geometric calibration process. The calibration process determined focal length, distortions of camera and projector lenses, the relative position of the camera and projector towards each other. The excellent calibration results for the camera, projector and the system were between 0.2 to 0.5 Pixels Root Mean Square (RMS) errors. The calibration was achieved with a standard calibration board size, $21 \times 15$ squares $(25 \times 18 \mathrm{~cm})$. However, the calibration board can be enlarged or reduced according to the object size. The calibration and scanning process were conducted while the artificial and natural light were eliminated.

A separate Mephisto process software was used to clean all the reconstructed data from the noise, to integrate them into the main data, and to align and post-processing all the data. The final outcome was a 3D model of the wounded area with recognizable geometry and color textured information. The Pico scan 3D scanner was able to require the color information simultaneously. However, the structured light 3D scanners (ATOS II and III) ${ }^{26,36}$ require placing reference markers around the wounded area to merge a color photo with a 3D geometry, which is a time-consuming step. ${ }^{38}$ According to the manufacture specifications of the Pico Scan 3D scanner, the results had a point to point distance of $0.16 \mathrm{~mm}$ and a point accuracy of 0.1 $\mathrm{mm}$.

The 3D scanning of the wounded area was conducted by following guidelines that are recommended in Shamata and Thompson, ${ }^{46}$ these guidelines are:

- Scanning only the injured surface of the body area in the stable manner was used as a standard 3D scanning technique.

- The number of scans of the relevant surface were more than three. However, only 2 scans were sufficient for a flat mode visualization.

- Three different scanning approaches were followed to enable the scanner accessing different areas of the upper limb, lower limb and torso. The participants were aware to maintain the same position during the scanning.

The final 3D model was visualized in the flat mode in the 3D MeshLab software.

\subsubsection{Nikon D70 digital camera}

The Nikon D70 has a sensor of 6.24-megapixels and focal length ranged from 18-70 mm. A close-up lens, Hoya ( +4$)$, was screwed over the primary lens to allow the primary lens focus more closely to the injuries. The manual mode was used to choose an appropriate aperture, shutter speed and ISO. The used f-stop was between $\mathrm{f} / 4-\mathrm{f} / 6.3$, the shutter speed was around 
1/30s and ISO was 400. Two different focal lengths were used in each photography: one focal length was around $35 \mathrm{~mm}$ and the second one was around $40 \mathrm{~mm}$.

The injuries located on different body areas so that the camera was handheld, ensured to be at proper angle as much as possible to minimize the angular distortion. The injuries were captured in the closest distance in which the image was in focus. A rigid straight photographic scale was placed around the injury. It was placed on the surface of the skin, on the same injury's plane. A ring light flash was not used.

\subsection{Wound measurements}

The recorded injuries that had length dimension, such as superficial incised wounds, stitched cut wounds, longitudinal abrasions and scratches were used to take measurements for comparisons. The wound measurements were taken manually and digitally. The manual wound measurements were taken during the medico-legal examination by using a tape measure. The digital wound measurements were taken from the $2 \mathrm{D}$ photos and the $3 \mathrm{D}$ models and called $2 \mathrm{D}$ and $3 \mathrm{D}$ measurements. The 2D wound measurements were taken after uploading the 2D photos into the software Image $J$, it is free and open source software (http://rsbweb.nih.gov/ij/download.html). The scale was used to calibrate linear dimensions on the photo. The 3D wound measurements were taken after importing the $3 \mathrm{D}$ model into the $3 \mathrm{D}$ MeshLab software, it is also free and open source software (http://www.meshlab.net/\#download). All measurements were taken from the same starting point of the recorded dimensions.

\subsection{Statistical analysis}

The statistical analysis was achieved using IBM SPSS Statistics 23 software. The wound measurements were statistically analysed by Friedman test to determine whether there was a statistical significant difference between the mean of the ordinary and 3D wound measurements. The Friedman test was used instead of One-way repeated measures ANOVA test because the collected data were not-normally distributed. Spearman's Rank-Order Correlation was considered to determine the relationship between the measurement methods. Intra observer reliability of the $3 \mathrm{D}$ and $2 \mathrm{D}$ wound measurements was evaluated using intraclass correlation coefficient test. The test compared two sets each of the 3D and 2D wound measurements that were taken from the same injuries on two different occasions by one observer. Two-way mixed model and absolute agreement were selected.

\section{Results}

Fifty-seven wounded live cases participated. Fifty were males and seven were females. Different types of forensic injuries were recorded by both methods and tabulated in Table 1 . 


\begin{tabular}{|c|c|c|c|c|}
\hline $\begin{array}{c}\text { Blunt force } \\
\text { injuries }\end{array}$ & $\begin{array}{c}\text { Sharp force } \\
\text { injuries }\end{array}$ & $\begin{array}{c}\text { Firearm } \\
\text { injuries }\end{array}$ & $\begin{array}{c}\text { Unclassified } \\
\text { injuries }\end{array}$ & Swelling \\
\hline 16 abrasions & $\begin{array}{c}11 \text { stitched cut } \\
\text { wounds }\end{array}$ & $\begin{array}{c}3 \text { recent \& } 4 \\
\text { old. }\end{array}$ & 2 & 1 \\
\hline 9 bruises & $\begin{array}{c}6 \text { superficial } \\
\text { incised wounds }\end{array}$ & & & \\
\hline 2 abraded bruises & $\begin{array}{c}3 \text { stitched stab } \\
\text { wounds }\end{array}$ & & & \\
\hline 2 contused & & & & \\
\hline wounds & & & & \\
\hline
\end{tabular}

Table. 1. Types and number of recorded injuries by both methods: Ordinary digital photography and structured light 3D surface scanning.

\subsection{Comparison between the 3D and $2 \mathrm{D}$ wound documents}

Although the general presentation of both documents on the screen were almost similar, the 3D scanner was able to produce similar results of the photography without using the magnifying lens. Also, the 3D outcomes of the 3D surface scanning had extra features over the 2D outcomes of the digital photography, these features are illustrated in the following points:

-The 3D surface scanning computed the 3D coordinates $(x, y, z)$ of scanned surface points and represented the 3D surface geometry of the scanned area; therefore, the shape of the wounded areas in the 3D documents was closer to the real form. Fig. 2 and Fig. 3 show the same injury (small ordinary contused wound with swelling) in the $3 \mathrm{D}$ and $2 \mathrm{D}$ results, the $3 \mathrm{D}$ result was able to represent the $3 \mathrm{D}$ surface geometry of the wounded area while the $2 \mathrm{D}$ result was flat image having only two axes $(x \& y)$.

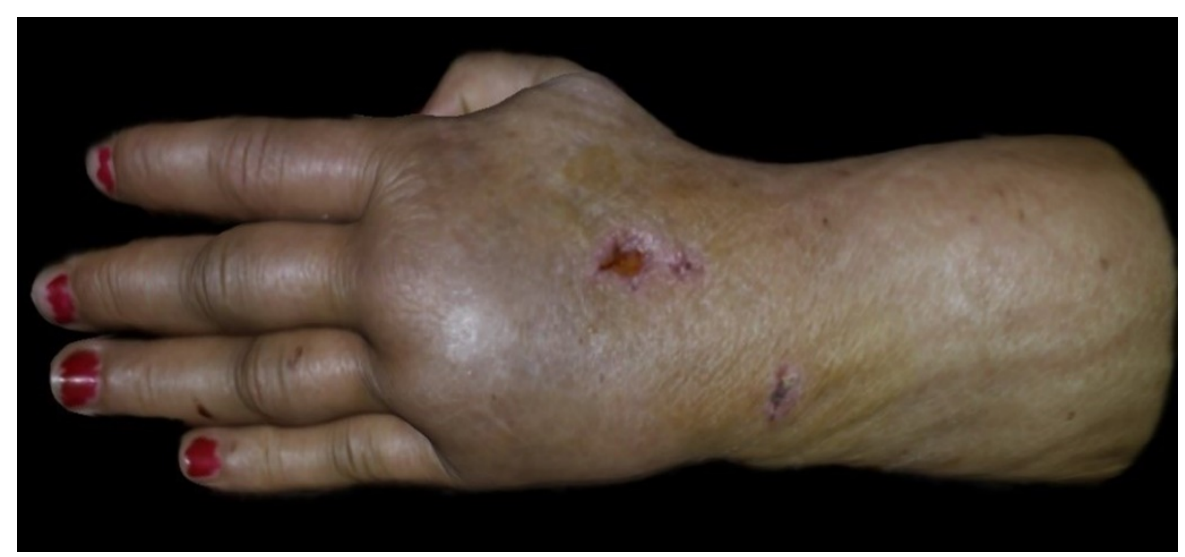


Fig.2. Snapped image from 3D model shows small ordinary contused wound with moderate swelling on the dorsal aspect of the left hand. The 3D result represents the 3D surface geometry of the wounded area. The 3D model can be found in a video 2 in the supplementary material.

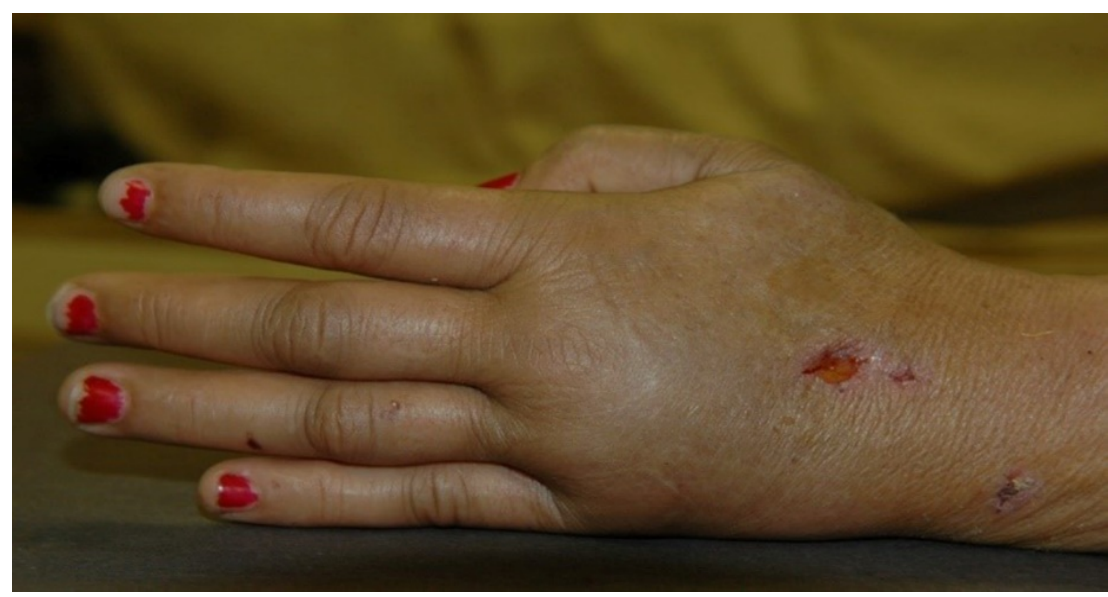

Fig.3. Digital photo of the same injury in the Fig. 2 shows flat 2D image.

-The 3D documents had unique ability to be manipulated on the monitor (Video 1 and Video 2 in the supplementary material). The manipulation allowed the examiner to do more visualization, to follow the direction of some injuries, and to pick an exact starting point of the greatest wound dimensions. While the $2 \mathrm{D}$ results were static images could not be manipulated on the screen.

- The scanner scanned the area of interest between the determined distance. The minimum distance was $100 \mathrm{~mm}$ and the maximum distance was around $700 \mathrm{~mm}$. Any objects beyond the maximum distance could be acquired as noise within the 3D data set; however, this kind of noise were eliminated by using a black screen. ${ }^{46}$ Any other unwanted, surrounding items within the determined distance were removed manually before the post-processing. Therefore, the final 3D image displayed only the injured area without clutters. While the 2D image is usually crowded as the 2D image has depth of the field. It can expose the interested object with background and foreground clutters. However, the close-up photography produces an image with no much depth of the field, especially if it works with longer focal length.

-When the injury was distributed on larger surface such as fabricated multiple superficial incised wounds on the back, the 3D surface scanner was able to reconstruct almost the full image of the wounded area. Whereas, the close-up digital photography with longer focal length reduced the total recorded area. Another example was two healed bite marks on the anterior aspect of the right forearm. The 3D scanner reconstructed the full image of both bite marks in 
one 3D model while the close-up digital photography captured each bite mark in a separate 2D image. It should be mentioned that reconstruction of the full image of the wounded area by the 3D scanner is entirely based on the calibration board size.

-The 3D results had actual size, did not require placing a scale around the injury. The 3D results without scale provided extra advantages, such as the 3D documents had no scale distortions, there was no possibility to obscure findings by the scale, wound measurements were achieved quickly, and there was no risk of infection. While the $2 \mathrm{D}$ results require a scale. The ABFO No. 2 scale is widely used as a standard reference scale in the forensic digital photography; however, according to Ferrucci et al. ${ }^{51}$ 'a review of commercially available photography scales shows a lack of consistency in quality and accuracy'.

-Finally, the clarity of the 3D documents was good. The 3D surface scanning was carried out in the dark room, only the scanner emitted direct structured white light to illuminate the surface of the wounded area. The shutter speed and ISO were within recommended values. The aperture opening (f-stop) was decided during the calibration process to avoid under or over exposure, all these factors contributed to minimize the exposure problems and produce clear $3 \mathrm{D}$ results. The clarity of the $3 \mathrm{D}$ documents was supportive in the wound interpretation. It was very useful to interpret the colour change of new bruises. In clinical forensic medicine, the colour change of the bruise is used roughly to estimate the time of the impact. Fig. 4 shows a bruise in the $3 \mathrm{D}$ result with clear colour change and Fig. 5 the same trauma in the $2 \mathrm{D}$ result. The document clarity was also useful to recognize the older bruise when there were multiple bruises on different occasions. Moreover, although the cut wounds were stitched, their 3D outcomes were clear, the wound edges, margins and angles all were clear and interpreted easily. In Fig. 6 can see clear stitched cut wounds in the 3D models and Fig. 7 shows the same wound in the digital image. The healing process of a stitched cut wound was also exposed clearly. While, in the digital photography the ISO, shutter speed and aperture values required more considerations, the clarity of the $2 \mathrm{D}$ results was also based on the photographer skills and experience. In addition, the close-up photography could produce $2 \mathrm{D}$ images with darker exposure as the intensity of light that reaches the sensor can be reduced, ${ }^{52,53}$ Fig. 5 shows a trauma in the 2D results with little darker exposure; however, the darker exposure of the closeup photography can be improved by adding light, using special kind of flashes, or using exposure adjustment in the Photoshop. 




Fig.4. Snapped image from 3D model shows clear colour change of the bruise on the posterior aspect of the right arm.

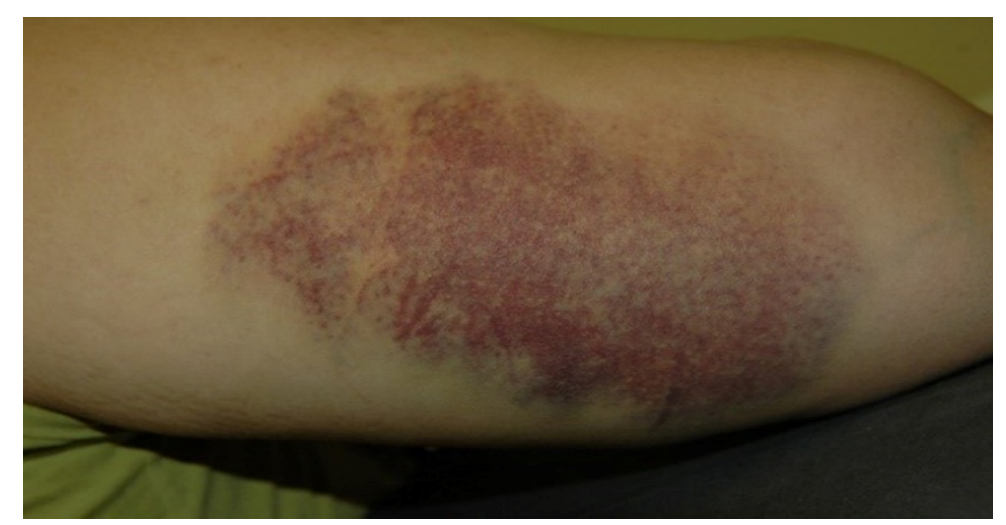

Fig. 5. Digital photo of the same injury in the Fig. 4.

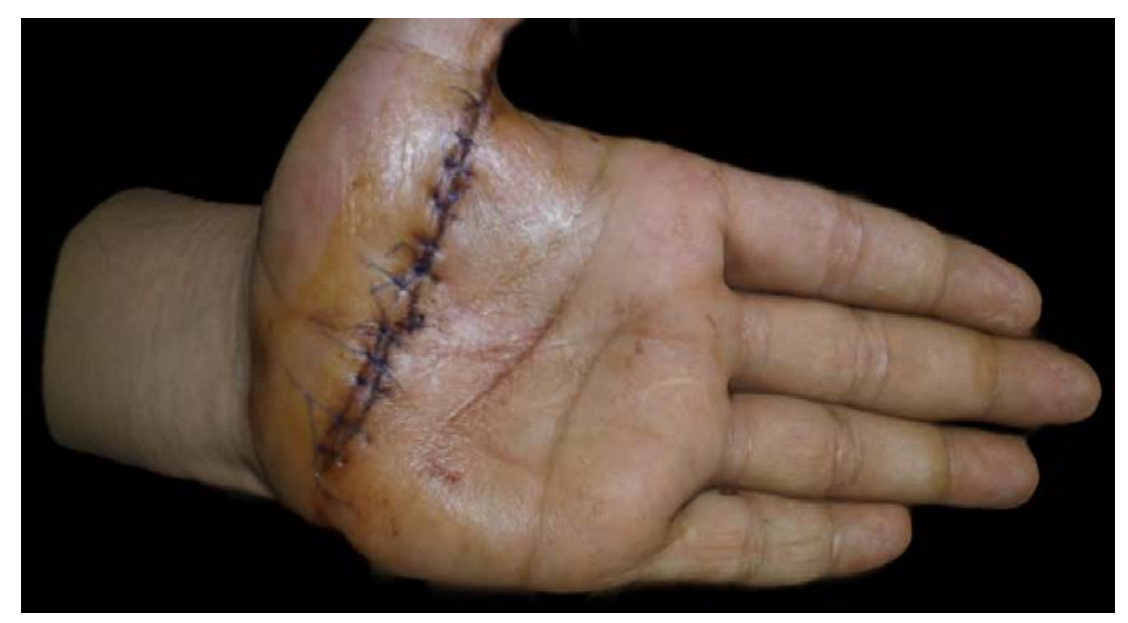

Fig. 6. Snapped image from 3D model shows stitched cut wound, defence wound, in the palmar aspect of the right hand. The $3 \mathrm{D}$ result represents clear stitched cut wound. The 3D model can be found in a video 1 in the supplementary material. 


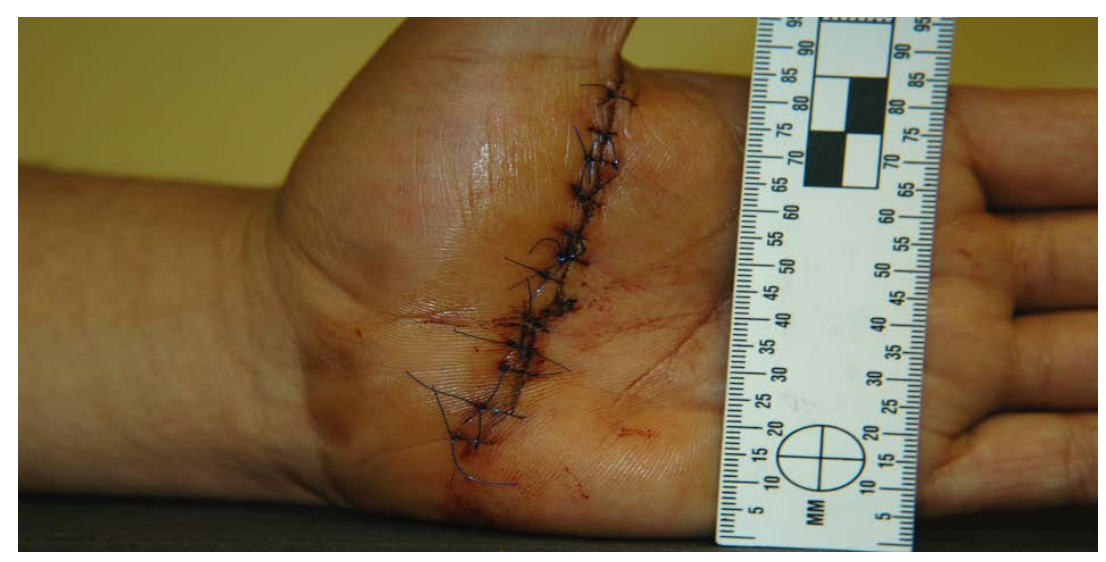

Fig. 7. Digital photo of the same injury in the Fig. 6. Very little exposure adjustment in the Photoshop was done in this photo.

\subsection{Comparison between the $3 \mathrm{D}$ and conventional wound measurements}

Twenty-one wounds were selected and measured using three measurement methods (ruler, $2 \mathrm{D}$ and $3 \mathrm{D}$ approaches). The recorded dimensions ranged from 10 to $\approx 85 \mathrm{~mm}$ (Fig. 8 shows ruler, 2D and 3D digital wound measurements of the recorded dimensions). Table 2. shows the mean dimensions of each method. The Friedman test demonstrated that no statistically significant difference was found between the measurement methods, $\mathrm{x}^{2}(2)=0.857, \mathrm{p}=0.651$. The Spearman's correlation established strong, positive correlations between the $3 \mathrm{D}$ and conventional measurement methods, which were statistically significant. The correlation between the ruler and 3D wound measurements was $(\mathrm{rs}(19)=0.954, \mathrm{p}=0.000)$, the magnitude of the relationship was $91 \%$, and the correlation between the 2D and 3D wound measurements was $(\mathrm{rs}(19)=0.992, \mathrm{p}=0.000)$, the magnitude of the relationship was $98 \%$. The relationship between the $2 \mathrm{D}$ and $3 \mathrm{D}$ method was stronger than the relationship between the ruler and 3D method. The intra-class correlation coefficient was excellent $(\mathrm{ICC}=0.999)$, when the 3D wound measurements were taken from the same 21 wounds by the same observer on two different occasions; however, the excellent ICC was also observed with the 2D wound measurements $(\mathrm{ICC}=0.991)$. 


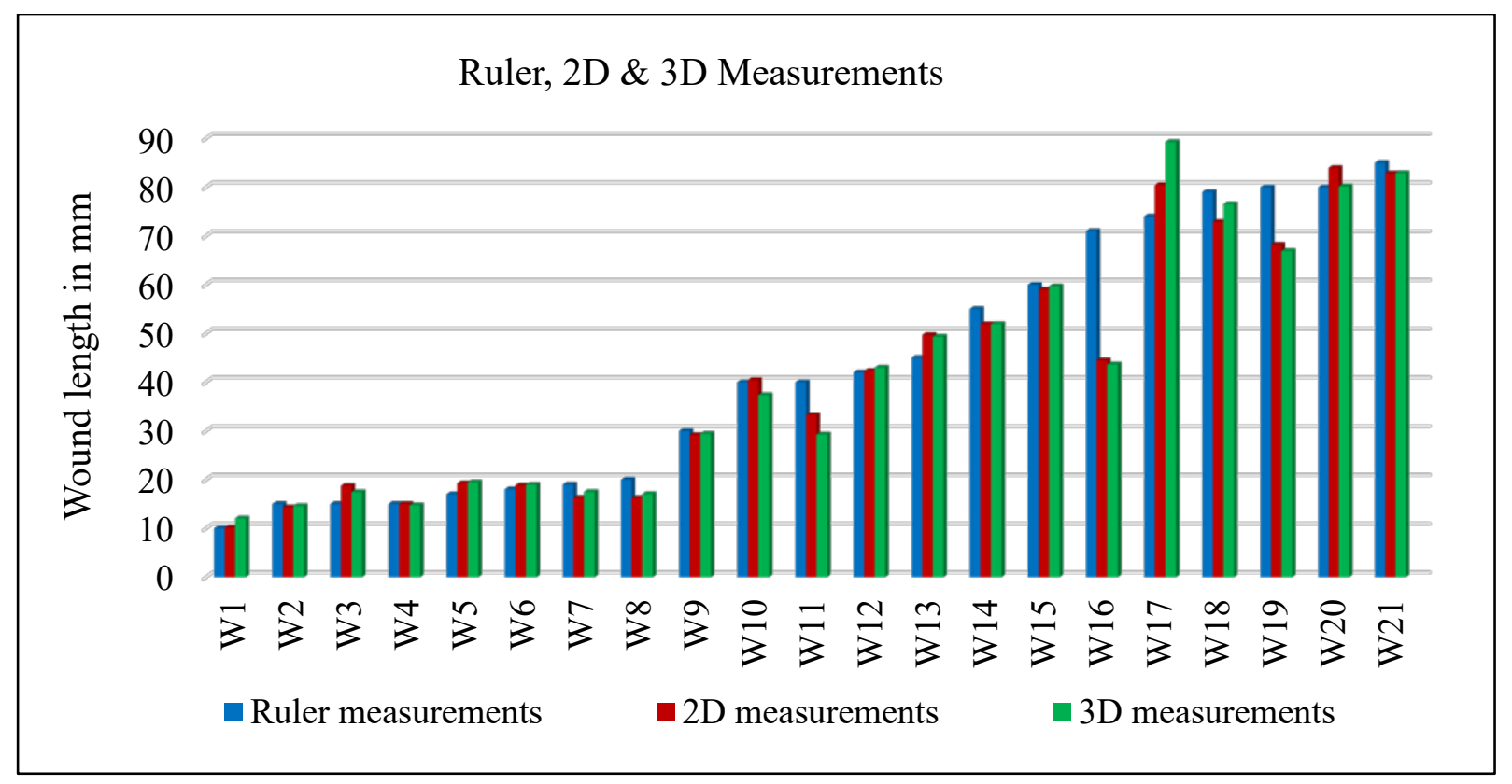

Fig. 8. Ruler, 2D and 3D wound measurements of the same 21 wounds.

\begin{tabular}{|l|c|r|c|}
\hline \multicolumn{1}{|c|}{ Measurements } & Mean & Std. Deviation & N. \\
\hline Ruler measurements. & 43.3333 & 26.46948 & 21 \\
\hline 2D measurements. & 41.2957 & 25.15682 & 21 \\
\hline 3D measurements. & 41.4733 & 25.72461 & 21 \\
\hline
\end{tabular}

Table 2. Descriptive statistics of measurement results.

\section{Discussion}

The importance of the 3D surface scanner is producing 3D models with an extra dimension (Z-axis) so that scanning of open injuries with depth information (in forensic pathology) is more valuable than scanning closed injuries, such as abrasion, bruise, stitched wounds (in clinical forensic medicine). However, both types of the injuries (open and closed) have medicolegal importance. In the clinical forensic medicine, the examiner writes medico- legal reports about the injuries, which are mostly closed injuries, explaining, for instance, thy type of the injury, the expected causative tool, whether the injury will cause permanent infirmity. Also, he should write about the wound dimensions or wound area. Prosecutors rely on these reports to categorize the crime into minor or major crime. The importance of these reports was the main motivation for applying the structured light 3D surface scanning in clinical forensic medicine and to know how helpful it will be in recording theses injuries.

Although the close-up lens was used with 2D digital photography, the structured light 3D surface scanner was able to impose its efficiency and generated appreciated 3D documents without using the magnifying lens. The 3D documents represented the 3D surface geometry of 
the wounded area, had ability to be manipulated on the monitor, displayed only the wounded area without extra information, had actual size, and scanning did not require a scale, and reconstructed almost the full image of the wounded area; in addition to the clarity of the 3D documents. While the 2D results were flat and static, had a photographic scale, could expose the wanted area with clutters, and could have poor exposure, especially if the photographer has no enough experience.

From a technical point of view, the structured light 3D method was able to overcome the main known deficiencies of the digital photography that are related to the lighting condition, angle of acquisition, and the distance. The scanning was conducted in the room with no artificial or natural light as stronger lighting condition can compete with the structured light resulting in poor $3 \mathrm{D}$ reconstructed data. ${ }^{54}$ While the lighting condition is not easy to control during the ordinary digital photography. ${ }^{2-7}$ Three different scanning approaches ${ }^{46}$ were followed to access injuries in different areas of the body, these approaches aimed to make the scanned area facing the scanner (the projector and camera) in the parallel way. However, Casas et al..$^{5}$ stated that " $3 D$ methods have been developed to obtain more accurate measurements without the constraint of the view-angle of a device". While slight change in the camera position (the angle of the photography) can have a negative impact on the $2 \mathrm{D}$ results. ${ }^{3,8,25}$ The distance was determined in the scanning options of the PicoScan3 software. The scanner scanned the wanted area between the determined distance. While, the 2D results can be affected by improper distance. ${ }^{1}$ However, the close-up photography was used in this work, the images were captured in the closest distance in which the image was in focus.

Moreover, the 3D active surface scanning technique of the Pico Scan is known to be an accurate and robust. The Pico scan 3D scanner projects structured light patterns with coding strategy that allows an accurate correspondence between the projected image and captured image. ${ }^{30,31,39-42}$ The Pico Scan 3D scanner uses the PMP technique which is an accurate and robust principle having high speed 3D reconstruction. ${ }^{41,44}$ Moreover, the scanning must be preceded by the geometric calibration process that uses a very robust and accurate algorithm. ${ }^{46-}$ 50

However, the $3 \mathrm{D}$ reconstruction process of the injuries of the live subjects faced some difficulties, for example, slight change of the posture of the scanned area (mainly areas of the lower limb) caused overlapping artefact in the final 3D result; however, scanning the area more than three times and post-processing only the scans that had the same posture solved this issue. Breathing process was another issue. ${ }^{46}$ However, very quiet, cooperative volunteers in the sitting position almost eliminated the negative impacts of the breathing. Scanning only the 
injured surface was used as a standard 3D scanning technique; therefore, an extended injury that had more than one surface was not reconstructed completely. Wounds those located on unreachable body sites such as postero-medial surface of the arm were not easily accessed. Smaller wounds such as inlet of firearm injuries were not clearly reconstructed. The calibration was achieved with the standard calibration board size $(25 \times 18 \mathrm{~cm})$, using smaller calibration board can solve this issue. However, using the calibration board corresponding to each injury size will not be practical. Therefore, the automatic calibration of hand-held scanner is highly recommended to be designed.

The cost of the 3D scanner is another limiting factor. ${ }^{36}$ The Pico Scan structured light 3D surface scanner costed around $£ 1995.00$, which was about 20 times more than the cost of the used camera (Nikon D70).

3D data size is based on details, size of the scanned area, and the number of the scans. In some situations, the data may require more than a standard computer for post-processing and storage. ${ }^{36,37}$

No statistically significant difference between the 3D wound measurements and conventional measurements was generally agreed with the result of Villa ${ }^{38}$; however, she has compared ruler and 3D wound measurements that are based on photogrammetry, passive 3D surface scanning. No statistically significant difference between the $3 \mathrm{D}$ and conventional wound measurements was a primary evidence providing the validity of the $3 \mathrm{D}$ wound measurements. The Spearman's correlation between the 2D and 3D wound measurements was stronger than the correlation between the ruler and 3D wound measurements. This is because the wound measurements of $2 \mathrm{D}$ and $3 \mathrm{D}$ relied on a computer, the mouse cursor was used to recognize the exact starting point of the maximum dimension, and the measurements were not influenced by skin elasticity, movements, or change in subject's position. For that reason, wound measurements based on computer have higher level of reliability. ${ }^{12}$

Table 3. Shows differentiating features of the ruler, 2D and 3D wound measurement methods.

Depth dimension was not considered in this study, as mentioned earlier the work was conducted in the clinical forensic medicine, the volunteers were wounded live victims, obtained medical intervention before the medico-legal examination. Therefore, cut, stab, contused wounds were stitched, and almost all recorded injuries were closed having length \pm width dimensions except the firearm injuries. Therefore, a further study will be conducted in forensic pathology during external post-mortem examination to scan the open injuries and to evaluate depth dimensions. 


\begin{tabular}{|c|c|c|c|}
\hline Feature & $\begin{array}{c}\text { Ruler measurement } \\
\text { method }\end{array}$ & $\begin{array}{c}\text { 2D measurement } \\
\text { method }\end{array}$ & $\begin{array}{c}\text { 3D measurement } \\
\text { method }\end{array}$ \\
\hline $\begin{array}{l}\text { Risk of } \\
\text { infection }\end{array}$ & $\begin{array}{l}\text { Contact method, has } \\
\text { risk of infection. }\end{array}$ & $\begin{array}{l}\text { Contact method, has risk } \\
\text { of infection. }\end{array}$ & $\begin{array}{l}\text { Non-contact method, } \\
\text { has no risk of infection. }\end{array}$ \\
\hline Scale required & -------------- & $\begin{array}{l}\text { It requires placing a } \\
\text { scale around the wound } \\
\text { during the photography. }\end{array}$ & $\begin{array}{l}\text { It does not need a scale } \\
\text { during scanning as the } \\
\text { results are actual size. }\end{array}$ \\
\hline $\begin{array}{l}\text { Permanent } \\
\text { records }\end{array}$ & $\begin{array}{l}\text { It has no permanent } \\
\text { records. }\end{array}$ & $\begin{array}{l}\text { It provides permanent } \\
\text { records with wound } \\
\text { appearance and color. }\end{array}$ & $\begin{array}{l}\text { It provides permanent } \\
\text { records with wound } 3 \mathrm{D} \\
\text { surface geometry and } \\
\text { colored textured } \\
\text { information. }\end{array}$ \\
\hline $\begin{array}{l}\text { The natural } \\
\text { curvature of } \\
\text { the body }\end{array}$ & $\begin{array}{l}\text { It considers the body } \\
\text { curvature. }^{4} \text { A tape } \\
\text { measure can be used } \\
\text { instead of a rigid ruler } \\
\text { for curved area. }\end{array}$ & $\begin{array}{l}\text { It does not consider the } \\
\text { body curvature. }{ }^{18}\end{array}$ & $\begin{array}{l}\text { It does not consider the } \\
\text { body curvature. }{ }^{18}\end{array}$ \\
\hline $\begin{array}{l}\text { Measurement } \\
\text { information }\end{array}$ & $\begin{array}{l}\text { Linear dimensions } \\
\text { (length and width). }\end{array}$ & $\begin{array}{l}\text { linear dimensions and } \\
\text { wound areas. }\end{array}$ & $\begin{array}{l}\text { It can provide more } \\
\text { measurement } \\
\text { information, such as } \\
\text { depth and } \\
\text { volume. }\end{array}$ \\
\hline $\begin{array}{l}\text { Depth } \\
\text { measurements }\end{array}$ & $\begin{array}{l}\text { Depth is measured by } \\
\text { invasive tools, such as } \\
\text { an electronic caliber or } \\
\text { Q-tip. }\end{array}$ & $\begin{array}{l}\text { Depth information } \\
\text { cannot be obtained from } \\
\text { 2D flat photos. }\end{array}$ & $\begin{array}{l}\text { Depth or volume can be } \\
\text { measured by } 3 \mathrm{D} \\
\text { software. }^{15,28}\end{array}$ \\
\hline $\begin{array}{l}\text { Area } \\
\text { measurements }\end{array}$ & $\begin{array}{l}\text { It can overestimate the } \\
\text { actual area of the } \\
\text { wound by } 10 \% \text { to } \\
44 \% .{ }^{3,4,7}\end{array}$ & $\begin{array}{l}\text { It can underestimate the } \\
\text { wound area by up } 10 \% \\
\text { to } 34.8 \%, 3,25 \text { or } \\
\text { overestimate the area. }\end{array}$ & $\begin{array}{l}\text { It is an effective } \\
\text { method for measuring } \\
\text { the surface area. }{ }^{55}\end{array}$ \\
\hline $\begin{array}{l}\text { Impacting } \\
\text { factors }\end{array}$ & $\begin{array}{l}\text { Movements and } \\
\text { change in subject } \\
\text { position have impacts }\end{array}$ & $\begin{array}{l}\text { Distance, }^{1} \text { lighting } \\
\text { condition, }^{2-7} \text { angle of } \\
\text { acquisition }^{3,8,25} \text { have }\end{array}$ & $\begin{array}{l}\text { It is developed to be } \\
\text { more } \quad \text { controlled } \\
\text { method. }{ }^{5} \quad \text { Lighting }\end{array}$ \\
\hline
\end{tabular}




\begin{tabular}{|c|c|c|c|}
\hline & $\begin{array}{l}\text { on the wound } \\
\text { measurements. }{ }^{18}\end{array}$ & $\begin{array}{l}\text { impacts on the } \\
\text { measurements. }\end{array}$ & $\begin{array}{l}\text { condition, angle of } \\
\text { acquisition and distance } \\
\text { are under control. }\end{array}$ \\
\hline Reliability & $\begin{array}{l}\text { Subjective method, } \\
\text { limited by Inter- } \\
\text { observer variability. } \\
15\end{array}$ & $\begin{array}{l}\text { Has low Inter-observer } \\
\text { variation. }{ }^{3,14}\end{array}$ & $\begin{array}{l}\text { It has a lowest Inter- } \\
\text { observer error. }{ }^{15,18}\end{array}$ \\
\hline Accuracy & $\begin{array}{l}\text { It has a questionable } \\
\text { accuracy. }{ }^{12,13,21,22}\end{array}$ & $\begin{array}{l}\text { It provides accurate } \\
\text { measurements. }^{3,4,14}\end{array}$ & $\begin{array}{l}\text { It has greater accuracy } \\
\text { when compared to } \\
\text { conventional } \\
\text { methods. }^{15}\end{array}$ \\
\hline
\end{tabular}

Table 3. The differentiating features of the ruler, 2D and 3D measurement methods.

(2D measurement method relies on the 2D photos, and 3D measurement method relies on the 3D models)

\section{Conclusion}

The Pico Scan, structured light, 3D surface scanner was appreciated in scanning the forensic injuries of live cases. The 3D documentation results of the surface scanning had extra features over the $2 \mathrm{D}$ results of the ordinary digital photography. The $3 \mathrm{D}$ results represented the $3 \mathrm{D}$ surface geometry of the wounded area, had ability to be manipulated on the monitor, displayed only the injured area without clutters, had actual size and the scale was not required, recorded almost the full image of the injured area; in addition to the clarity of the $3 \mathrm{D}$ results. These advantages had significant roles during injury interpretation and will have role during injury presentation inside the court. While the $2 \mathrm{D}$ results were flat and static, had a photographic scale, could expose the wanted area with the clutters, and could have poor exposure. Moreover, the $3 \mathrm{D}$ scanning method was able to overcome the main deficiencies of the digital photography that are related to the lighting condition, angle of acquisition, and distance. The study established the validity of 3D wound measurements that were based on the structure light 3D surface scanning technique. The next study will be performed in forensic pathology to evaluate open injuries with depth information. The accuracy of 3D wound measurements, and the reliability with more than one assessor will be considered. 


\section{References}

1.Verhoff MV, Kettner M, Lászik A, Ramsthaler F. Digital Photo Documentation of Forensically Relevant Injuries as Part of the Clinical First Response Protocol. Dtsch Arztebl Int. 2012; 109: 638-642. Doi: 10.3238/arztebl.2012.0638.

2.Green WM and Schulman E. Forensic Photography. In: Riviello R J, ed. Manual of forensic emergency medicine: A guide for Clinicians. Jones and Bartlett Publisher. 2010; 44-58.

3.Chang AC, Dearman B. and Greenwood JE. Comparison of Wound Area Measurement Techniques: Visitrak versus Photography. Eplasty Journal. 2011; 11:158-166.

4.Shaw $J$ and Bell PM. Wound Measurement in Diabetic Foot Ulceration. http://cdn.intechweb.org/pdfs/24689.pdf; 2011 Accessed 8.11.2017.

5.Casas L, Castaneda B, Treuillet S. Imaging technology applied to chronic wounds: a survey. Proceedings of the 4th International Symposium on Applied Sciences in Biomedical and Communication Technologies. 2011, Barcelona, Spain; 1-5. Doi: 10.1145/2093698.2093865.

6.Marsh NP. The photography of injuries. In: Gall J. and Payne-James J, eds. Current practice in forensic medicine. John Wiley \& Sons, Ltd. 2011; 159-192.

7.Pavlovcic P, Diaci J, Mozina J, Jezersek M. Wound perimeter, area, and volume measurement based on laser 3D and colour acquisition. BioMedical Engineering OnLine. 2015; 14:39. Doi: 10.1186/s12938-015-0031-7.

8.Evans S, Baylis S, Carabott R, Jones M, Kelson Z, Marsh N, Payne-James J, Ramadani J, Vanezis P, Kemp A. Guidelines for photography of cutaneous marks and injuries: a multiprofessional perspective. Journal of Visual Communication in Medicine. 2014; 37:3-12. Doi: $10.3109 / 17453054.2014 .911152$.

9.Boyat AK and Joshi BK. A Review Paper: Noise Models in Digital Image Processing. Signal and Image Processing: International Journal (SIPIJ). 2015; 6: 63- 75. Doi: 10.5121/sipij.2015.6206.

10. Verme R and Ali J. A Comparative Study of Various Types of Image Noise and Efficient Noise Removal Techniques. International Journal of Advanced Research in Computer Science and Software Engineering. 2013; 3: 617-622.

11.Payne-James JJ. Rules and scales used in measurement in the forensic setting: measuredand found wanting. Forensic Science Medicine Pathology. 2012; 8: 482-483. Doi: $10.1007 / \mathrm{s} 12024-012-9320-7$.

12.Majeske C. Reliability of wound surface area measurements. Physical Therapy Journal. 1992; 72: 138-141. 
13.Haghpanah S, Bogie K, Wang X, Banks PG, Ho CH. Reliability of Electronic Versus Manual Wound Measurement Techniques. Archives of physical medicine and rehabilitation. 2006; 87: 1396-1402. Doi: 10.1016/j.apmr.2006.06.014.

14.Rogers LC, Bevilacqua NJ, Armstrong DG, Andros G. Digital planimetry results in more accurate wound measurements: a comparison to standard ruler measurements. Journal of Diabetes Science and technology. 2010; 4: 799-802. Doi: 10.1177/193229681000400405.

15.Shah A, Wollak C, Shah JB. Wound Measurement Techniques: Comparing the Use of Ruler Method, 2D Imaging and 3D Scanner. Journal of American College of Clinical Wound Specialist. 2015; 5: 52-57.

16.Thawer HA, Houghton PE, Woodbury MG, Keast D, Campbell K. A comparison of computer-assisted and manual wound size measurement. Ostomy Wound Management Journal. 2002; 48: 46-53.

17.Diane L, Julie A, Darlene H, Patricia D. Measuring wound length, width, and area: which technique? Advances in skin and wound care. 2008; 21: 42-45. Doi: 10.1097/01.ASW.0000284967.69863.2f.

18.Plassmann P and Jones TD. MAVIS: a non-invasive instrument to measure area and volume of wounds. Medical Engineering \& Physics Journal. 1998; 20: 332-338. Doi: 10.1016/S13504533(98)00034-4.

19.Fette AM. A clinimetric analysis of wound measurement tools. http://www.worldwidewounds.com/2006/january/Fette/Clinimetric-Analysis-Wound-

Measurement-Tools.html; 2006 Accessed 30.01. 2017.

20.Bowling F, King L, Fadavit H, Paterson JA, Preece K, Daniel RW, Matthews DJ, Boulton AJ. An assessment of the accuracy and usability of a novel optical wound measurement system. Diabetic Medicine. 2009; 26: 93-96. Doi: 10.1111/j.1464-5491.2008.02611. x.

21.Goldman R J and Salcido R. More than One Way to Measure a Wound: An Overview of Tools and Techniques. Advances in Skin \& Wound Care Journal. 2002; 15: 236-243.

22.Shetty R, Sreekar H, Lamba S, Gupta AK. A novel and accurate technique of photographic wound measurement. Indian Journal of Plastic Surgery. 2012; 45: 425 - 429. Doi: 10.4103/0970-0358.101333.

23.Bianco M and Williams C. Using photography in wound assessment. Practice Nurses. 2002; 13: 505-508.

24. Thali MJ, Braun M, Brueschweiler W, Dirnhofer R. 'Morphology imprint' determination of the injury-causing weapon from the wound morphology using forensic 3D/CAD- suspected 
photogrammetry. Forensic Science International Journal. 2003; 132: 177-81. Doi: http://dx.doi.org/10.1016/S0379-0738(03)00021-5.

25.Foltynski P, Ladyzynski P, Ciechanowska A, Migalska-Musial K, Judzewicz G, Sabalinska S. Wound Area Measurement with Digital Planimetry: Improved Accuracy and Precision with Calibration Based on 2 Ruler. PLoS One. 2015; 10: e0134622. Doi: 10.1371/journal.pone.0134622.

26.Thali MJ, Braun M, Dirnhofer R. Optical 3D surface digitizing in forensic medicine: 3D documentation of skin and bone injuries. Forensic Science International Journal. 2003; 137: 203-208. Doi: 10.1016/j.forsciint.2003.07.009.

27.Bruschweiler W, Braun M, Dirnhofer R, Thali MJ. Analysis of patterned injuries and injurycausing instruments with forensic 3D/CAD supported photogrammetry (FPHG): an instruction manual for the documentation processes. Forensic Science International Journal. 2003; 132:130-138. Doi:10.1016/S0379-0738(03)00006-9.

28.Sansoni G, Cattaneo C, Trebeschi M, Gibelli D, Porta D, Picozzi M. Feasibility of contactless 3D optical measurement for the analysis of bone and soft tissue lesions: new technologies and perspectives in forensic sciences. Journal of Forensic Science. 2009; 54: 540545. Doi: 10.1111/j.1556-4029.2009. 01041.x.

29. De Sainte Croix MM, Gauld D, Forgie AH, Lowe R. Three- dimensional imaging of human cutaneous forearm bite marks in human volunteers over a 4-day period. Journal of Forensic and Legal Medicine. 2016; 40: 34-39. Doi: 10.1016/j.jflm.2016.02.003.

30.Geng J. Structured-light 3D surface imaging: a tutorial. Advances in Optics and Photonics Journal. 2011; 3: 128-160. Doi: 10.1364/AOP.3.000128.

31.Salvi J, Fernandez S, Pribanic T, Llado X. A state of the art in structured light patterns for surface profilometry. Pattern Recognition Journal. 2010; 43: 2666-2680. Doi: 10.1016/j.patcog.2010.03.004.

32.Errickson D, Thompson TJU, Rankin BWJ. The application of 3D visualization of osteological trauma for the courtroom: A critical review. Journal of Forensic Pathology and Imaging. 2014; 2: 132-137. Doi: 10.1016/j.jofri.2014.04.002.

33.Ozturk C, Dubin S, Schafer ME, Shi W, Chou M. A new structured light method for 3-D wound measurement. Proceedings of the IEEE 22 $2^{\text {nd }}$ Annual Northeast Bioengineering Conference. 1996; 70-71. Doi: 10.1109/NEBC.1996.503222.

34.Callieri M, Cignoni P, Pingi P, Scopigno R, Coluccia M, Gaggio G, et al. Derma: Monitoring the Evolution of Skin Lesions with a 3D System. 8th International Fall Workshop on VISION, MODELING, AND VISUALIZATION. 2003. 
35.Subke J, Wehner HD, Wehner F, Szczepaniak S. Streifenlichttopometrie (SLT): a new method for three-dimensional photorealistic forensic documentation in colour. Forensic Science International. 2000; 113: 289-295. Doi: 10.1016/S0379-0738(00)00236-X.

36. Ebert LC, Flach P, Schweitzer W, Leipner A, Kottner S, Gascho D, Thali MJ, Breitbeck R. Forensic 3D surface documentation at the Institute of Forensic Medicine in Zurich-workflow and communication pipeline. Journal of Forensic Radiology and Imaging. 2015; 5: 1-7. Doi: 10.1016/j.jofri.2015.11.007.

37.Urbanova P, Hejna P, Jurda M. Testing photogrammetry-based techniques for threedimensional surface documentation in forensic pathology. Forensic Science International Journal. 2015; 250: 77-86. Doi: http://dx.doi.org/10.1016/j.forsciint.2015.03.005.

38.Villa C. Forensic 3D documentation of skin injuries. International Journal of Legal Medicine. 2017; 131: 751-759. Doi: 10.1007/s00414-016-1499-9.

39.Ishii I. A Coded Structured Light Projection Method for High-Frame-Rate 3D Image Acquisition. http://cdn.intechopen.com/pdfs-wm/32185.pdf; 2012 Accessed 27.10. 2016.

40.Yalla VG, Hassebrook LG. Very high resolutions 3D surface scanning using multifrequency phase measuring profilometry. Proceedings of SPIE 5798, Spaceborne Sensors II. 2005. Doi: $10.1117 / 12.603832$.

41.Wang Y, Liu K, Hao Qi, Lau D, Hassebrook L. Multicamera Phase Measuring Profilometry for Accurate Depth Measurement. Proceeding of SPIE 6555, Sensors and Systems for Scape Applications, 655509. 2007. Doi: 10.1117/12.720068.

42.Salvi J, Pages J, Batlle J. Pattern codification strategy in structured light systems. Pattern Recognition Journal. 2004; 37: 827-849. Doi: 10.1016/j.patcog.2003.10.002.

43. Georgopoulos A, Ioannidis $\mathrm{CH}$, Valanis A. Assessing the performance of a structured light scanner. International Archives of Photogrammetry, Remote Sensing and Spatial Information Sciences. 2010; 5: 250 - 255.

44.Lohry W F, Chen V, Zhang S. Absolute three-dimensional shape measurement using coded fringe patterns without phase unwrapping or projector calibration. Optics Express Journal. 2014; 22: 1287-1301. Doi: 10.1364/OE.22.001287.

45. John Tzou C, Artner NM, Pona I, Hold A, Placheta E, Kropatsch WG, Frey M. Comparison of three-dimensional surface-imaging systems. Journal of Plastic, Reconstructive and Aesthetic Surgery. 2014; 67: 489-497. Doi: 10.1016/j.bjps.2014.01.003. 
46. Shamata A and Thompson TJU. Using structured light three- dimensional surface scanning on living individuals: key considerations and best practice for forensic medicine. Journal of Forensic and Legal Medicine. 2018; 55: 58-64. DOI: 10.1016/j.jflm.2018.02.017.

47.Errickson D, Thompson T, Rankin B. An Optimum Guide for the Reduction of Noise using a Surface Scanner for Digitising Human Osteological Remains. http://www.guides.archaeologydataservice.ac.uk/g2gp/CS_StructuredLight; 2015 Accessed 20. 09. 2016.

48. Errickson D, Grueso I, Griffith SJ, Setchell JM, Thompson TJU, Thompson CEL, Gowland RL. Towards a Best Practice for the Use of Active Non-contact Surface Scanning to Record Human Skeletal Remains from Archaeological Contexts. International Journal of Osteoarchaeology. 2017; 27:650-661. DOI: 10.1002/oa.2587.

49. Thompson TJU and Norris P. A new method for the recovery and evidential comparison of footwear impressions using 3D structured light scanning. Science and Justice. 2018 DOI:10.1016/j.scijus.2018.02.001.

50. Pandy SC and Cather S. Close-range 3D imaging for documentation and monitoring dynamic deterioration process in wall painting. http://network.icom.museum/fileadmin/user_upload/minisites/cidoc/BoardMeetings/Satish_P andey.pdf; 2016 Accessed 15. 07. 2016.

51. Ferrucci M, Doiron TD, Thompson RM, Jones JP, Freeman AJ, Neiman JA. Dimensional Review of Scales for Forensic Photography. Journal of Forensic Sciences. 2016; 61: 509 - 519. DOI: $10.1111 / 1556-4029.12976$.

52.Constant AR. Close-up photography. Boston Oxford: Focal press; 2000.

53.Foster GV and Barker NJ. Close-Up Photography of Archaeological Objects. Journal of Field Archaeology. 1996; 23: 369 - 375. Doi: 10.1179/009346996791973864.

54.Gupta M, Yin Q, Nayar SK. Structured Light In Sunlight. IEEE International Conference on Computer Vision, Sydney, NSW, Australia, 1-8 Dec. 2013; 545-552. Doi: 10.1109/ICCV.2013.73.

55.Krouskop TA, Baker R, Wilson MS. A noncontact wound measurement system. Journal of Rehabilitation Research and Development. 2002; 39: 337-346. 